\title{
Differential patterns of semaphorin expression in the developing rat brain
}

\author{
Irini Skaliora, Wolf Singer, ${ }^{1}$ Heinrich Betz ${ }^{2}$ and Andreas W. Püschel ${ }^{2}$ \\ Laboratory of Physiology, University of Oxford, Parks Road, Oxford OX1 3PT, UK \\ ${ }^{1}$ Department of Neurophysiology, Max-Planck-Institut für Hirnforschung, Deutschordenstrasse 46, D-60528 Frankfurt/Main, \\ Germany \\ ${ }^{2}$ Department of Neurochemistry, Max-Planck-Institut für Hirnforschung, Deutschordenstrasse 46, D-60528 Frankfurt/Main, \\ Germany
}

Keywords: axon guidance, chemorepulsion, cortical development, rat, thalamocortical connections

\begin{abstract}
Semaphorins are a large family of cell-surface and secreted proteins that have been shown to function as chemorepellents or inhibitors of growth cones of peripheral neurons, yet little is known about their role in patterning central pathways. In order to examine whether semaphorins may be involved in guiding the formation of the reciprocal thalamocortical connections in the rat, we have analysed the spatial and temporal expression of five recently identified rodent semaphorins ( $\operatorname{semB}, \mathrm{C}, \mathrm{D}, \mathrm{F}$ and $\mathrm{G}$ ) using in situ hybridization. Transcripts of all five genes were present throughout the period examined (E15-P7) and displayed highly specific spatiotemporal distributions. We have based our discussion of putative semaphorin effects on their known functions as chemorepellents and found their spatiotemporal expression patterns compatible with such a role in several developmental events. Specifically, semaphorins are in the position to: (i) prevent neurite extension into the ventricular neuroepithelium throughout the brain; (ii) confer non-permissive properties to the embryonic cortical plate, hence regulating the radial invasion of corticopetal afferents; (iii) confine axonal extension to the intermediate zone and subplate; (iv) maintain the fasciculated state of thalamocortical and corticothalamic axons, and prevent them from branching while they grow through the striatum; and ( $v$ ) restrict the terminal arborizations of thalamic afferents to layer IV. The evidence that different semaphorin genes are often co-expressed further suggests that the various molecules might interact in synergistic ways. Taken together, our results support the hypothesis that semaphorins could act as guidance signals in the development of the thalamocortical projections and suggest that innervation specificity is achieved through the combined action of multiple guidance cues. Furthermore, these data provide a basis for the design of functional assays and the study of mice carrying knockouts in specific semaphorin genes.
\end{abstract}

\section{Introduction}

During development, axons often have to travel considerable distances and make a number of 'decisions' in choosing the correct route, finding their target region and selecting the appropriate synaptic partner within it. Tracing experiments indicate that axonal pathways can form with a high degree of precision from the outset and need not always rely on subsequent 'corrective' mechanisms (Crandall \& Caviness, 1984; Van Eden, 1986; Lent et al., 1990; Kageyama \& Robertson, 1993; Miller et al., 1993). This implies that molecular guidance cues can specify axonal projections with considerable accuracy.

Initially, most studies on the mechanisms of axonal navigation focused on signals attracting neuronal growth cones, including targetderived chemoattraction and differential adhesion (Sperry, 1963; see reviews by Jessell, 1988; Hortsch \& Goodman, 1991; Edelman \& Crossin, 1991). It gradually became clear, however, that regulation through growth cone collapse or repulsion may be an equally important guidance mechanism (Tosney \& Landmesser, 1984; Kapfhammer et al., 1986; Pini, 1993; see reviews by Schwab et al., 1993; Goodman \& Shatz, 1993; Dodd \& Schuchardt, 1995). In the last 2-3 years, different families of such repulsive proteins have been identified and among these the semaphorins occupy a prominent place. Initially identified independently in chick and grasshopper (Raper \& Kapfhammer, 1990; Kolodkin et al., 1992), the semaphorins are now known to consist of a diverse family of both secreted and membranebound proteins that are conserved from insects to humans, and comprise at least 20 members (e.g. Kolodkin et al., 1993; Messersmith et al., 1995; Luo et al., 1993, 1995; Wright et al., 1995; Adams et al., 1996; Culotti \& Kolodkin, 1996; Giger et al., 1996). In rodents, seven different semaphorins (semA-G) have been identified, all sharing a conserved extracellular domain of about 500 amino acids (Kolodkin et al., 1993; Luo et al., 1993; Püschel, 1996). So far, semaphorins have been associated with inhibitory effects on growth cones of 
peripheral neurons. Individual family members have been found to induce the collapse of chick sensory axons in vitro (collapsin; Raper \& Kapfhammer, 1990; Luo et al., 1993), to selectively inhibit the formation of terminal arborizations of Drosophila motor neurons (Dsema II; Matthes et al., 1995), to prevent branching and maintain the fasciculation of grasshopper motor neurons (G-sema I; Kolodkin et al., 1992), and to influence steering decisions of cultured sensory afferents in rat spinal cord (semD, H-sema III; Messersmith et al., 1995). However, permissive functions should not be excluded, in particular since two of the mammalian semaphorins contain additional domains that have been associated with neurite promoting effects (Adams et al., 1996).

The role of semaphorins in patterning central pathways is presently unclear, although recent gene deletion experiments in mice indicate that the lack of semaIII/semD results in severely reduced neuropil and abnormally orientated pyramidal cells in the cerebral cortex (Behar et al., 1996). Here, we examined whether semaphorins might represent molecular cues that guide the development of axonal projections between thalamus and cortex. Previous studies have revealed that the maturation of the cortical plate and the development of thalamocortical projections correlate with changes in certain extracellular matrix components and cell adhesion molecules (Fushiki \& Schachner, 1986; Chun \& Shatz, 1988; Sheppard et al., 1991; Chung et al., 1991; Oohira et al., 1991; Bicknese et al., 1994; Miller et al., 1995). Some of the respective molecules affect neurite growth in vitro, but it is often not clear whether they provide positive or negative signals (e.g. Lochter et al., 1991; Iijima et al., 1991; Friedlander et al., 1994). Tissue culture studies have shown that thalamic axons do not invade cortical explants until about E20 (Molnár \& Blakemore, 1991), and that they grow better on membrane preparations of postnatal rather than embryonic cortex (Götz et al., 1992; Tuttle et al., 1995). It has been inferred from such studies that immature cortex is a poor substrate for axonal extension, and that permissiveness develops gradually, from lower layers upwards, due to an upregulation of growth promoting molecules (Götz et al., 1992; Emerling \& Lander, 1994; Tuttle et al., 1995). Little attention has been paid to the alternative possibility that choice of routes and regulation of branching are controlled by inhibitory factors. Here we analyse the expression patterns of five members of the semaphorin family during embryonic and postnatal development of the rat brain (E15-P7), the time during which the reciprocal projections between thalamus and cortex (as well as several other axon pathways) are established. Our results indicate complex expression patterns of the individual semaphorin genes and lay the foundations for further functional assays aimed at elucidating the role of semaphorins in the development of cortical connectivity.

\section{Materials and methods}

Wistar rats were purchased from Harlan-Winkelmann Ltd. (Borchem, Germany). The day of vaginal plug detection was considered as embryonic day zero (E0). Pregnant females were killed by an overdose of barbiturates, and the foetuses were removed and immediately postfixed at $4{ }^{\circ} \mathrm{C}$ with $4 \%$ (w/v) paraformaldehyde (PFA). Postnatal animals were killed in the same way and perfused with cold saline followed by 4\% PFA. On the next day, whole foetuses (E15-E17) or dissected brains (E19-P7) were dehydrated through a series of ethanol/ saline solutions, treated with xylene and embedded in paraplast. Sections were cut at $10 \mu \mathrm{m}$, mounted on TESPA-coated slides and processed for in situ hybridization using 35S-labelled RNA probes as described previously (Püschel et al., 1995). The following probes, cloned into Bluescript, were used as templates: 0.9-kb fragments generated by PCR for semB and C (Püschel et al., 1995); a 2.9-kb cDNA fragment for semD (Püschel et al., 1995); a 0.9-kb PCR fragment for semF (Adams et al., 1996); and a 1.1-kb cDNA fragment for semG (Adams et al., 1996). The procedure included an RNase treatment that ensures a high specificity of the probes, even with transcripts displaying a high degree of homology. The probes chosen were derived from regions which display a low degree of identity between different semaphorins and did not show cross-hybridization in previous experiments (Püschel et al., 1995, 1996; Adams et al., 1996).

For autoradiography, the slides were dipped in Kodak NTB-2 photographic emulsion, exposed for 2 weeks and developed in Kodak D-19 solution. The sections were counterstained with toluidine blue and mounted in Permount. For more accurate morphological identification, adjacent sections were Nissl-stained.

Representative sections were analysed under a light microscope and labelled structures were photographed using objectives of different magnifications $(1.25 \times$ to $10 \times)$. Low magnification darkfield pictures are used to provide overviews of semaphorin expression, and high magnifications are presented where necessary. The location and boundaries of nuclei and cortical layers in the hybridized sections were determined with the help of adjacent Nissl-stained sections according to Paxinos et al. (1991) and Altman \& Bayer (1995). All expression patterns were verified in at least two animals.

\section{Results}

To determine the patterns of semaphorin expression during embryonic and postnatal development, we performed in situ hybridizations on coronal and sagittal sections from rat brains between E15 and P7 using 35S-labelled RNA probes specific for semaphorins B, C, D, F and G. We concentrated mainly on structures related to the development of the thalamocortical pathway, and therefore we describe expression patterns in the basal telencephalon, thalamus and cortex, although other major structures such as the hippocampus are also considered. First, we make some general comments on the semaphorin distribution patterns throughout the brain. We then provide, for each structure, a detailed analysis at E15 (earliest age examined), and subsequently describe the prominent changes in semaphorin expression as development proceeds and the mature organization emerges.

\section{General comments}

All five semaphorin genes were expressed during this developmental period, and each manifested a unique spatiotemporal pattern of expression (see Table 1), making it difficult to identify grouping criteria for data presentation. However, several observations and general principles deserve to be highlighted.

As a general rule, most structures examined contain transcripts of one or more (up to four) semaphorins at any given stage of development. Notable exceptions to this rule are the cortical intermediate zone and white matter, which, between E16 and P0, are devoid of semaphorin signals (e.g. Figs $2 \mathrm{~A}-\mathrm{F}$ and $3 \mathrm{D}-\mathrm{H}$ ); as well as cortical layer IV, in which none of the semaphorin genes is ever expressed (e.g. Figs 5D-H and 6A-C). In structures where several semaphorins are co-expressed, their hybridization signals often display very distinct patterns, suggesting the involvement of different cell populations [e.g. semD and $\mathrm{F}$ in cortical layer VI (Fig. 5-compare panels $D$ and $G$ ), or semD and $G$ in the postnatal corpus striatum (Figs 4A, 5I, 6B,C)]. This observation also argues against the possibility of cross-hybridization (see Methods).

Moreover, certain semaphorins appear to respect regional boundaries: semB transcripts are never found in the basal ganglia or the 
TABLE 1. Development of semaphorin expression patterns. The expression of the five different semaphorin mRNAs is colour coded: semB in yellow, semC in black, semD in red, semF in green and semG in blue. The intensity of the hybridization signal is indicated by the saturation of the colour

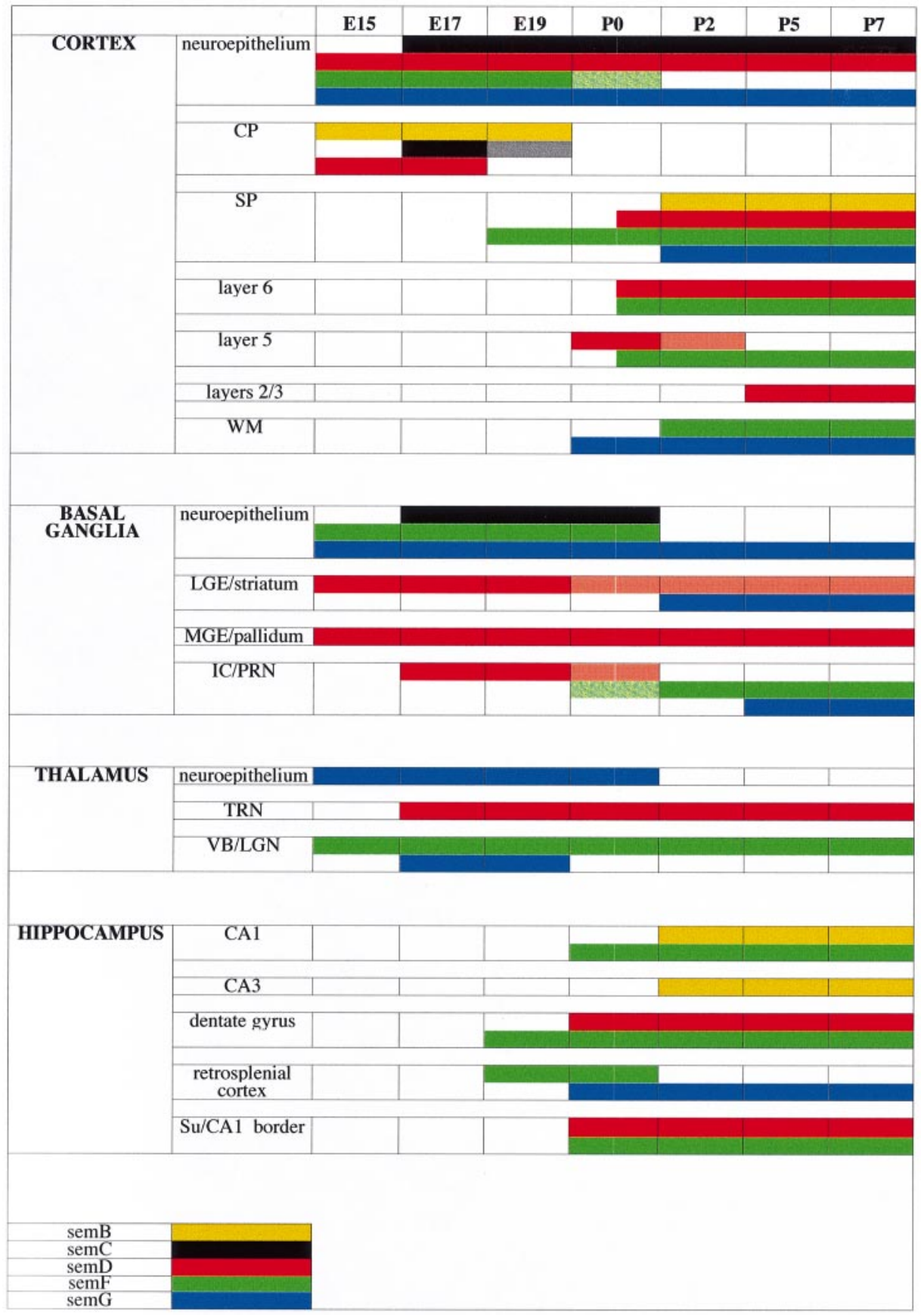

thalamus (Table 1), thus restricting their expression to structures derived from the dorsal telencephalon. Similarly, semC is never expressed in either the thalamus or the hippocampus, and within the other areas, semC transcripts are confined to the neuroepithelium and the cortical plate (e.g. Fig. 2E, see also Table 1). Localized semaphorin expression is also seen within the cortex. SemF transcripts are restricted to the subplate of dorsomedial (but not ventrolateral) cortex (Fig. 4H) and at later stages they display a patchy distribution within layer VI of sensorimotor (but not visual) cortex (Fig. 5J,K). In addition, semD signals, while initially homogeneously distributed in the supragranular layers of the entire cortical sheet, subsequently disappear selectively from the supragranular layers of the posterior (putative visual) cortex (e.g. Fig. 7B).

Finally, there are also cases where specific semaphorin expression is related to particular types of tissue rather than brain regions. SemG transcripts are always present in all neuroepithelia throughout the brain, implying a role associated with proliferative tissue in general (e.g. Figs 1E, 2F, 3C, etc.). Similarly, semF and G are the only two semaphorins that are ever seen in fibre tracts (cortical white matter, corpus callosum, internal capsule, e.g. Figs $5 \mathrm{~F}$ and $6 \mathrm{E}, \mathrm{F}$ ), and semB signals are never found in proliferative tissue (e.g. Fig. 1B; Table 1). 

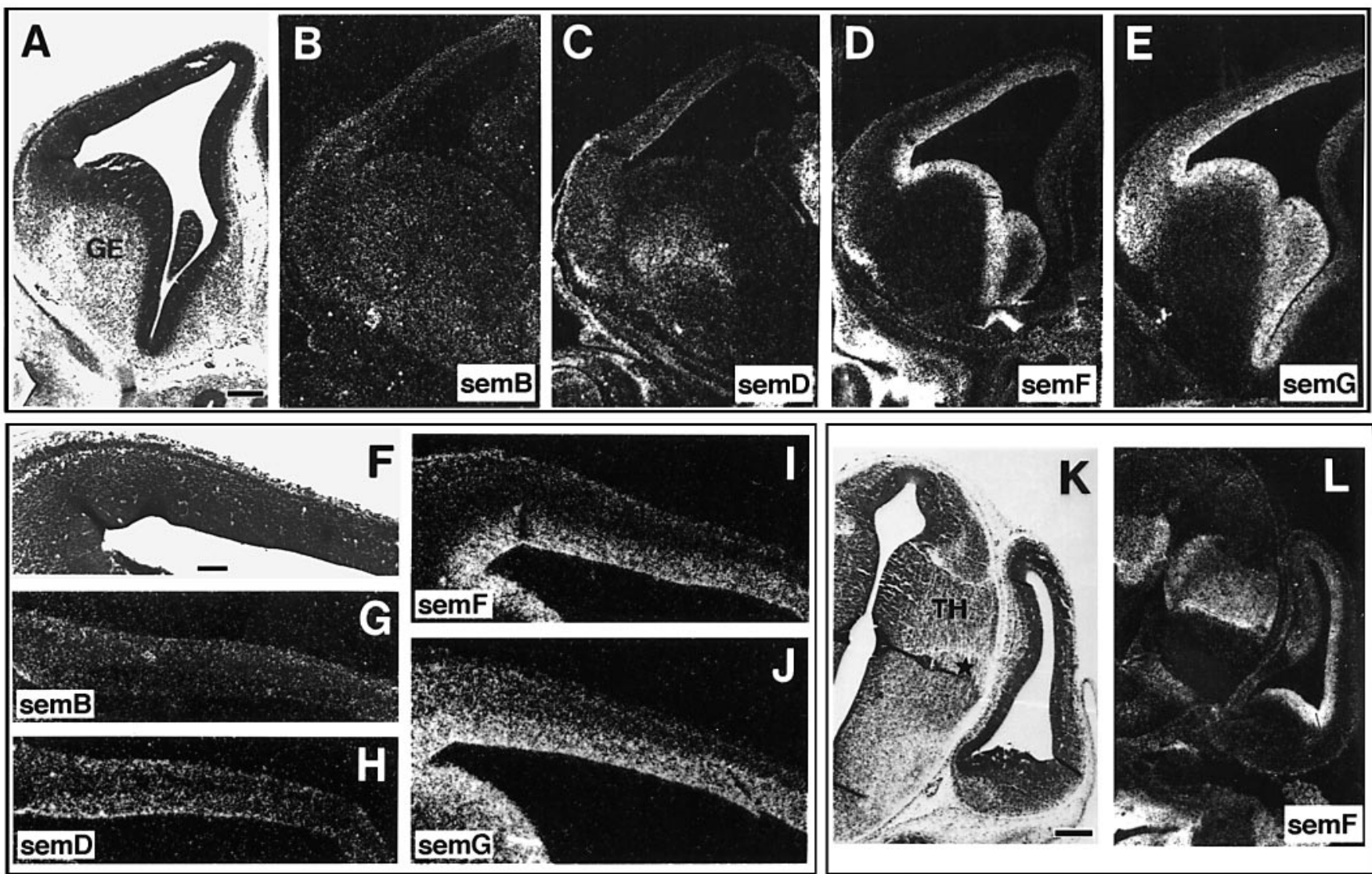

FIG. 1. Semaphorin expression at E15. Nissl-stained coronal section (A) and adjacent sections hybridized with probes specific for semB (B), semD (C), semF (D) and semG (E). Dorsal is to the top, medial to the right. (B) SemB shows only a weak signal in the CP. (C) SemD is expressed in the GE (future striatum/ pallidum), and also in the cortical VZ and the CP. (D) SemF is strongly expressed in the ventricular neuroepithelium of both the cortex and the basal ganglia, and also in the marginal zone. (E) SemG shows an equally strong hybridization signal in the two neuroepithelia, but in addition extends into the IZ in the cortex and the subventricular zone in the basal ganglia. (F)-(J) Higher magnification to illustrate cortical expression of semB (G), semD (H), semF (I) and semG (J). $(\mathrm{K}),(\mathrm{L})$ Nissl-stained and adjacent coronal sections through the thalamus. Only semF is detected in this region and its expression domain includes anterior and intermediate thalamic regions, with sharp borders both ventrally to the thalamic reticular nucleus (TRN) and dorsally to the habenular nucleus. Asterisk indicates the position of the TRN. GE: ganglionic eminence; TH: thalamus. Scale bars: (A)-(E) and (K), (L), $250 \mu \mathrm{m}$; (F)-(J), $100 \mu \mathrm{m}$.

\section{Differential expression of semaphorin genes in the basal telencephalon}

Axons from the thalamus and cortex enter the basal telencephalon from opposite ends at about E14.5, avoiding the ventricular neuroepithelium and confining their route to the ganglionic eminence (GE) as they grow past each other towards their respective targets.

At E15, semaphorin genes are already expressed in this region in distinct, complementary and partially overlapping domains that cover the entire structure. SemF and G transcripts are present at high levels in the germinal layers, with semF expression being limited to the ventricular zone, and that of semG also extending into the subventricular zone (Fig. 1D,E). SemD is also prominently expressed, but its domain is restricted to the ganglionic eminence (Fig. 1C), covering both the medial and lateral portions of this structure. This complementary distribution of semF and $\mathrm{G}$ in the neuroepithelium, and of semD in the GE is maintained throughout embryonic development.

At E17, semC expression appears in the neuroepithelium in a pattern that completely overlaps with the semF expression domain (Fig. 2E). Moreover, a strong semD hybridization signal can now be detected at the medial border of the basal telencephalon, just lateral to the internal capsule (IC; Fig. 2H). This region is contiguous with the ganglionic eminence (which also expresses semD) and corresponds to the perireticular nucleus (PRN, Clemence \& Mitrofanis, 1992; Mitrofanis, 1992).

By P0, expression of semC (not shown) and semF markedly decreases in the ventricular zone (Fig. 4B), and semD expression becomes more heterogeneous, being particularly strong in the pallidum and considerably weaker in the striatum (Fig. 4A). SemD expression is also downregulated in the region of the PRN, while a weak semF hybridization signal appears de novo in the same region (Fig. 4H). This late appearance of semF transcripts could be associated with either perireticular or glial cells. The simultaneous appearance of semF transcripts in other fibre tracts (e.g. cortical white matter and corpus callosum, see below) lends indirect support to the latter interpretation. Unlike the other transcripts, semG expression shows little variation and continues to be strong in the ventricular and subventricular zones (Fig. 4C).

By $\mathrm{P} 2$, semC and $\mathrm{F}$ transcripts have disappeared from the striatal epithelium (Fig. 5B; Table 1), and semD hybridization can no longer be detected in the PRN/IC region (Fig. $5 \mathrm{~N}$ ). In contrast, semF expression is now increased in this region (Fig. 5M) and remains at high levels for the remainder of the developmental period examined (Fig. 6E). The most salient change relative to the preceding stages is the appearance of semG transcripts in the developing striatum (Fig. 

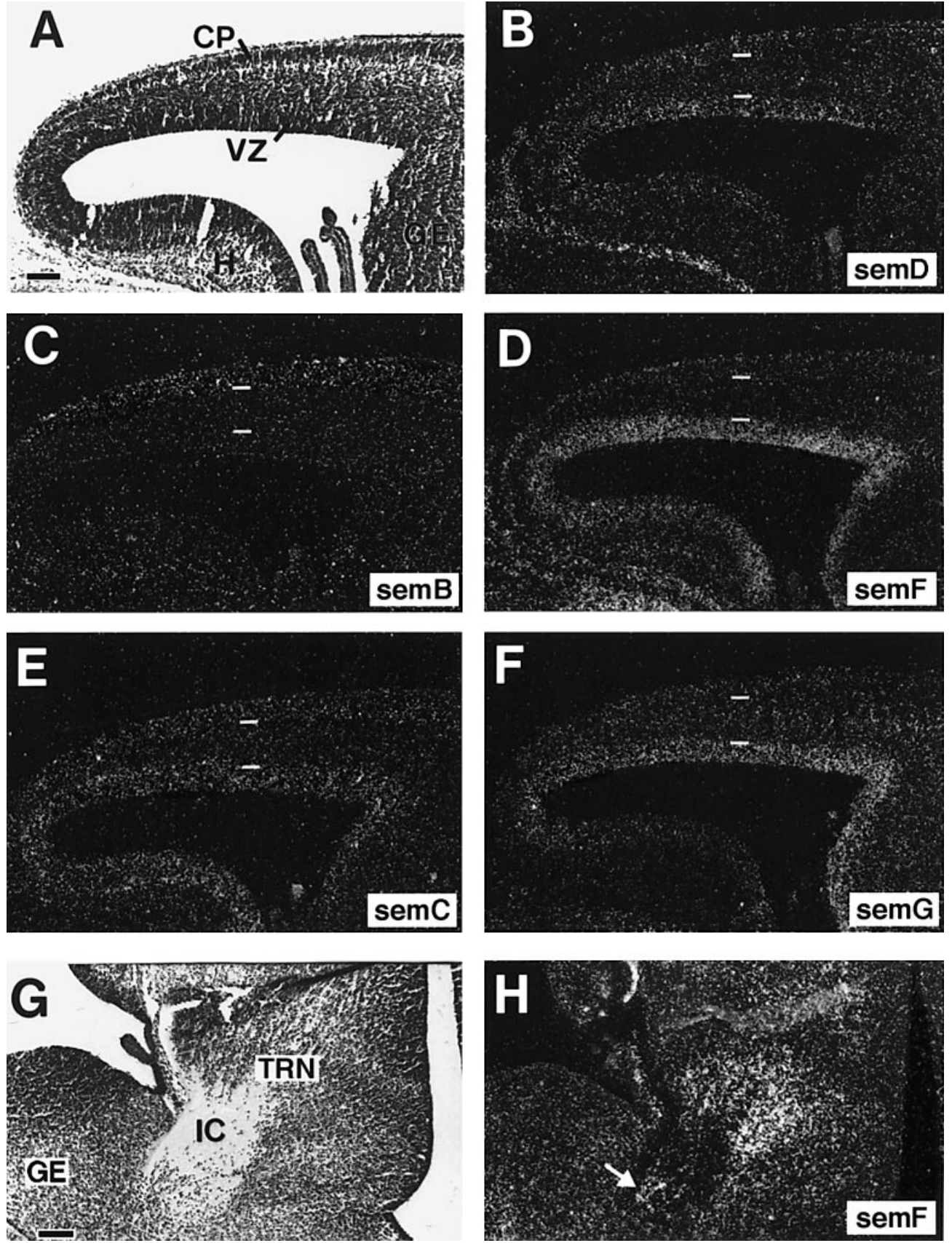

FIG. 2. Semaphorin expression patterns at E17. (A)-(F) Nissl-stained and adjacent coronal sections hybridized with probes specific for semD (B), semB (C), semF (D), semC (E) and semG (F). Dorsal is to the left, medial to the bottom. The short white lines indicate the lower border of the CP and the upper border of the VZ, respectively. (E) This age marks the onset of semC expression, with transcripts localized in the CP and also in the VZ of cortex, basal ganglia and hippocampus. The distribution of the other semaphorins in the cortex remains constant: $\operatorname{semF}(\mathrm{D})$ and semG (F) transcripts are restricted to the VZ, semB to the CP (C) and semC (E) and semD (B) are expressed in both the VZ and the CP. The IZ and WM are devoid of the five genes analysed. (G),(H) Coronal sections showing the onset of semD expression in the diencephalon. Dorsal is to the top, medial to the right. The highest accumulation of semD transcripts can be found in the TRN, just medial and dorsal to the fibres of the IC, although more dorsal thalamus also shows moderate expression. SemD is also present in the region of the perireticular nucleus (arrow). CP: cortical plate, VZ: ventricular zone, H: hippocampus, TRN: thalamic reticular nucleus, IC: internal capsule, GE: ganglionic eminence. Scale bars: $100 \mu \mathrm{m}$.

5I). SemG hybridization distributes in discrete patches within the striatum and thus exhibits a pattern very different from that of the homogeneously expressed semD in the same area. This suggests that semD and $\mathrm{G}$ are expressed by different subpopulations of cells and might serve different functional roles. The patches of semG expression are only seen in the striatum and not in the globus pallidus, and are particularly well defined in the dorsal part of this structure and become increasingly pronounced with age. The topology of these patches resembles closely that of the characteristic mosaic of patches and matrices within the neostriatum (Steindler et al., 1988; Ragsdale \& Graybiel, 1990; Gerfen, 1992), suggesting that semG might contribute to the formation of this pattern.

Beyond P2, semaphorin expression in the basal telencephalon changes very little, the main exception being the onset of semG 

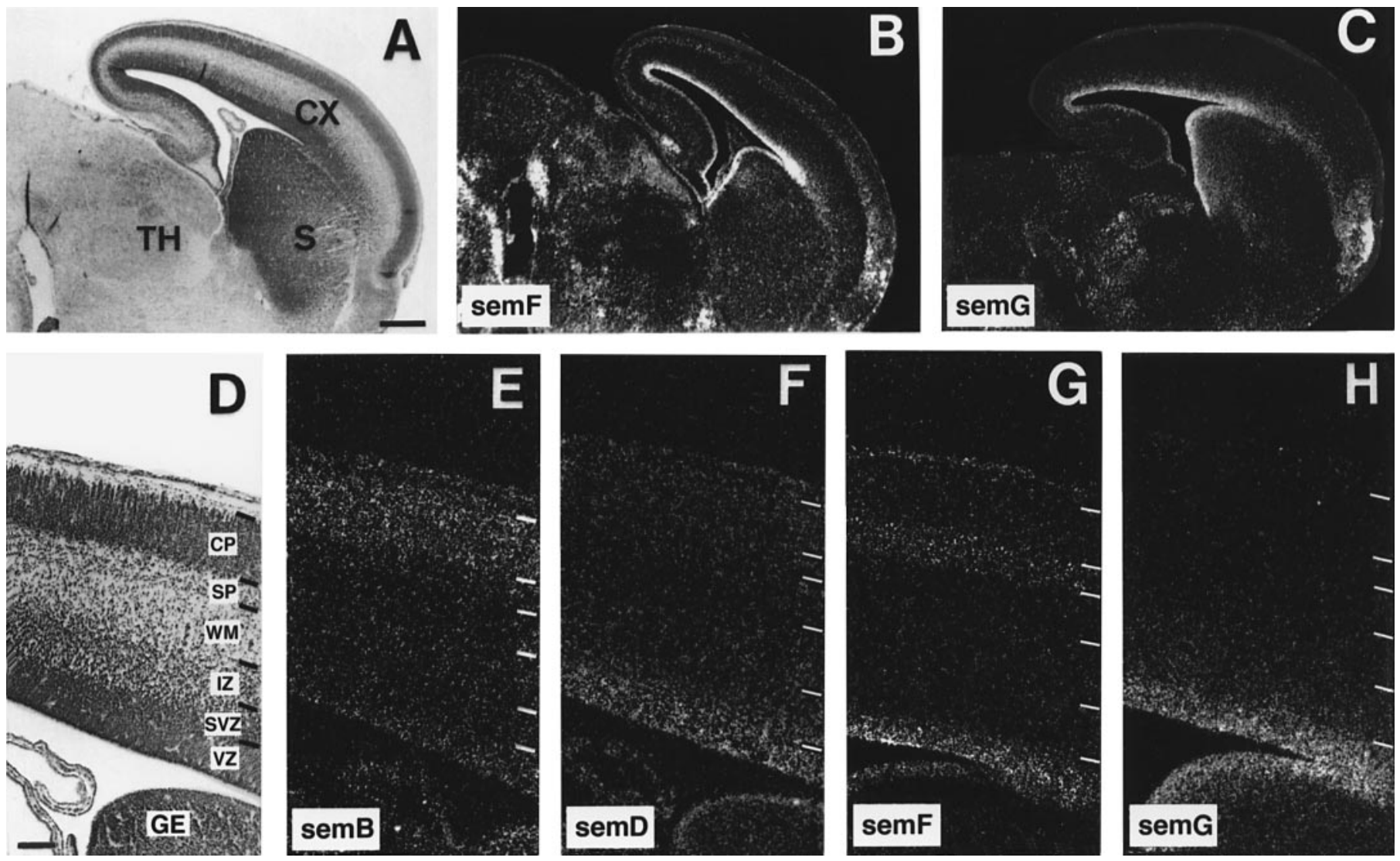

FIG. 3. Semaphorin expression at E19. (A)-(C) Adjacent parasagittal sections showing Nissl stain and hybridizations for semF (B) and semG (C). (D)-(H) High magnification views through the cerebral wall of consecutive sections hybridized with semB $(\mathrm{E})$, semD $(\mathrm{F})$, semF $(\mathrm{G})$ and $\operatorname{semG}(\mathrm{H})$. Dorsal is to the top, anterior to the right. (B), (F) SemF maintains a strong signal in the cortical and striatal neuroepithelia. In addition, there is now a distinct band of semF transcripts in the SP, which extends caudally into the subicular region of the hippocampus. SemF hybridization can also be found in the dentate gyrus. (C), (H) SemG expression is highest in the cortical and striatal VZ, and, unlike semF, also extends into the subventricular zones of both structures. (E) Transcripts for semB (and semC, not shown) are still present throughout the CP. (F) SemD transcripts are still present in the cortical epithelium but can no longer be detected in the CP. As before, the IZ and WM are devoid of the five genes analysed. Hybridization signals for semF (B) and semG (C) can also be found at the border between the GE and the cortical wall, a location that corresponds to the lateral migratory stream. CX: cortex, S: striatum, CP: cortical plate, SP: subplate, WM: white matter, IZ: intermediate zone, SVZ: subventricular zone, VZ: ventricular zone. Scale bars, (A)-(C): $500 \mu \mathrm{m}$; (D)-(H): $100 \mu \mathrm{m}$.

expression in the IC/PRN region at P5 (Fig. 6F, Table 1). The late appearance of this signal and its similarity to semF and semG labelling in other fibre tracts (see below) suggest a glial rather than a neuronal origin, especially since by this age the transient population of the PRN has already started to decrease (Earle \& Mitrofanis, 1996). Thus, at P7, only semD and G continue to be expressed in the basal telencephalon, with semG in the neuroepithelium, semD in the globus pallidus, and both semG and $\mathrm{D}$ in the striatum. At none of the stages examined did we find semB expression in these regions.

\section{Expression of semaphorins in the embryonic neocortex}

Axons from the thalamus enter the neocortex at about E16 and take an intracortical route that is restricted to the intermediate zone (IZ) and subplate (SP) layer.

Already at E15, all semaphorins except semC are expressed in the developing cerebral wall. Their distribution is characterized by intense and overlapping expression in the cortical plate (CP) and ventricular zone (VZ). SemF and G transcripts are abundant in the VZ, which, at this age, still occupies a large portion of the cerebral wall (Fig. $1 \mathrm{I}, \mathrm{J})$. SemD mRNA is also found in the VZ, albeit at somewhat lower levels (Fig. 1C,H). In the CP, both semB (Fig. 1B,G) and semD (Fig. $1 \mathrm{C}, \mathrm{H}$ ) are present. In contrast to the co-expression of several semaphorin genes in the ventricular zone and cortical plate, only one of them, semG, is detected in the region separating these two areas, the intermediate zone (Fig. 1J). The strong and overlapping semaphorin expression in the $\mathrm{CP}$ and $\mathrm{VZ}$ is maintained throughout embryonic development.

At E17, semG has disappeared from the IZ (Fig. 2F) and semC transcripts have appeared de novo in the ventricular zone and in the cortical plate (Fig. 2E). Thus, at E17 the stratified pattern of semaphorin expression already apparent at E15 becomes further accentuated, with two regions expressing high levels of semaphorin signals, the $\mathrm{CP}$ and the $\mathrm{VZ}$, flanking a region devoid of semaphorin transcripts, the IZ and accumulating white matter (WM).

As cortical maturation proceeds, distinct layers become recognizable. By E18-19, the subplate becomes morphologically distinguishable as early born SP neurons settle in a band below the developing CP (Fig. 3A,D). Substantial invasion into the cortical plate also begins at this stage, following the lateral-to-medial and anterior-to-posterior maturation gradients. There are two significant changes in semaphorin expression around this time: (i) semaphorins disappear from the cortical plate: semD transcripts can no longer be detected at E19 (Fig. 3F), while semB and C signals disappear sometime between E19 and P0 (Fig. 3E, Table 1); (ii) a distinct band of semF signals appears in the SP layer (Fig. 

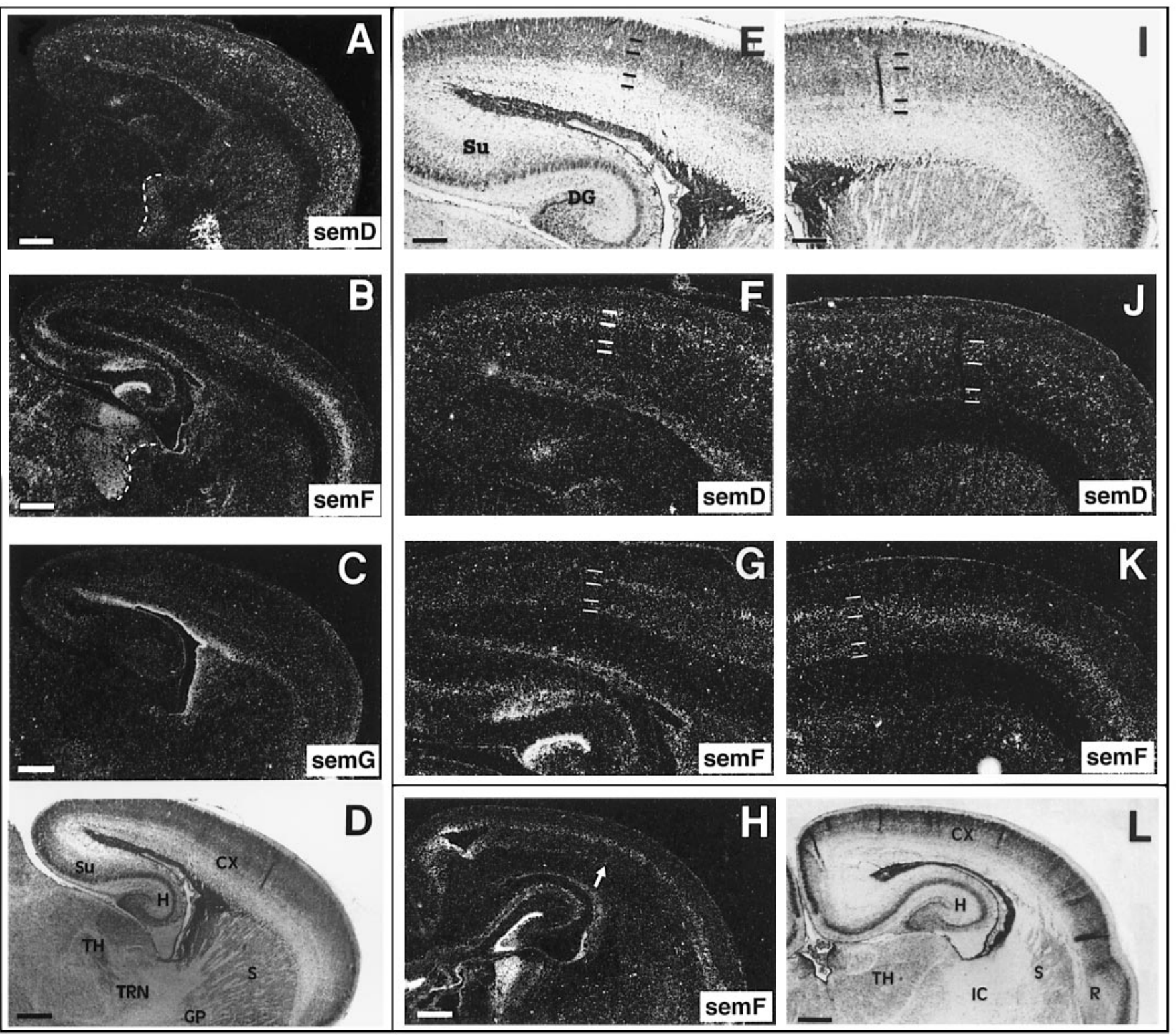

FIG. 4. Semaphorin expression at P0. (A)-(D) Parasagittal sections hybridized with probes specific for semD (A), semF (B) and semG (C) and adjacent Nisslstained section (D). Dorsal is to the top, anterior to the right. The dotted line in (A) and (B) indicates the posterior border of the TRN. (A) SemD transcripts continue to be present in the cortical VZ and, in addition, are beginning to appear in the SP and layers V and VI. The signal in SP and layer VI is more pronounced in anterior regions, as would be expected if expression follows the maturation gradient. SemD transcripts are still present in the TRN and in the basal ganglia. Unlike earlier ages, expression in the basal ganglia is now less uniform, with strong signals in the globus pallidus and weak ones in the striatum. (B) SemF hybridization is beginning to decrease in the $\mathrm{VZ}$ and can no longer be detected along the lateral migratory stream (LMS). In contrast, semF is still expressed in the SP, and can now also be detected in layer V. SemF expression in layer V is more pronounced in anterior cortex, where it also extends into upper layer VI. High levels of semF transcripts can still be found in anterior/intermediate thalamus and not in the TRN, hence complementing semD expression. Finally, there is now a particularly strong semF signal in the hippocampus, including the DG, CA1 and Su. SemF transcripts are also beginning to be detected in the choroid plexus in the ventricles. (C) SemG continues to be expressed in the telencephalic neuroepithelia and in the LMS, and is just beginning to be detectable in the cortical WM and the Su. In contrast, semG transcripts have completely disappeared from the thalamus. (E)-(G) and (I)-(K), higher magnification views of posterior and anterior cortex, respectively, to illustrate $\operatorname{semD}(\mathrm{F}, \mathrm{J})$ and $\operatorname{semF}(\mathrm{G}, \mathrm{K})$ expression in the cortical layers. The short white lines indicate the upper borders of layers V, VI, SP and WM, respectively. (H) Coronal section through central neocortex illustrating the regional specificity of semF expression in the SP, with transcripts present in dorsomedial but not in anterolateral cortex. In contrast, semF expression in layer $\mathrm{V}$ is uniform throughout the mediolateral extent of the cortical sheet. Arrow indicates the border of the semF expression domain in the SP. (L) Adjacent Nissl-stained section. Dorsal is to the top, medial to the left. CX: cortex, Su: subiculum, H: hippocampus, DG: dentate gyrus, TRN: thalamic reticular nucleus, GP: globus pallidus, S: striatum, TH: thalamus, IC: internal capsule, R: rhinencephalon. Scale bars: (A)-(D), (H) and (L), $500 \mu \mathrm{m} ;(\mathrm{E})-(\mathrm{G})$ and (I)-(K), $250 \mu \mathrm{m}$.

3B,G). Moreover, as the ventricular zone shrinks and the subventricular zone becomes more pronounced, the expression domains for semF and $\mathrm{G}$ start to differ, with semF being clearly restricted to the VZ, while
semG is also extending into the subventricular zone. Like at E17, the intermediate zone and white matter remain devoid of any of the analysed semaphorins. 

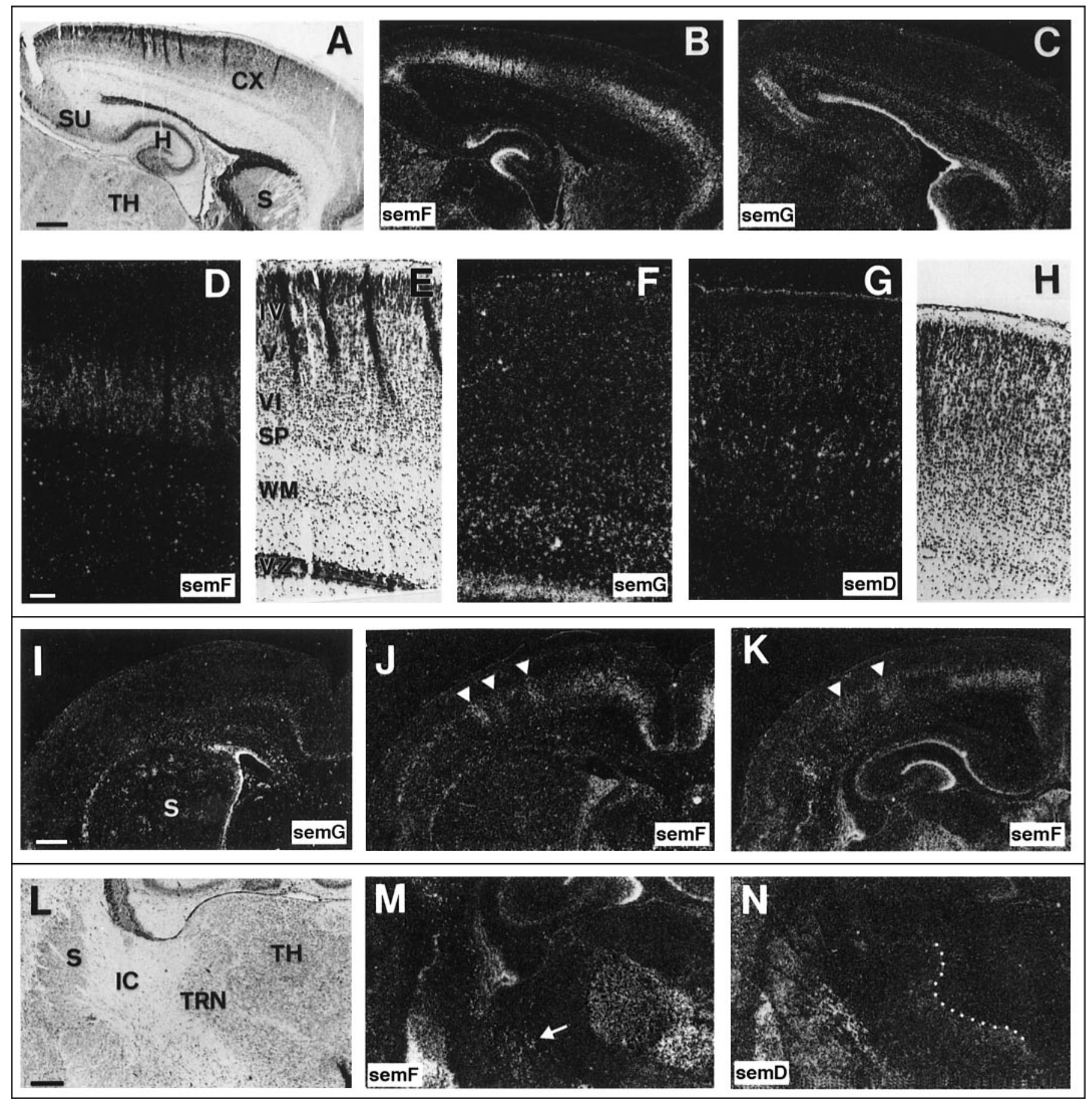

FIG. 5. Semaphorin expression at P2. Adjacent parasagittal sections showing Nissl stain (A) and hybridizations for semF (B) and G (C). Dorsal is to the top, anterior to the right. (B) SemF expression has disappeared from the cortical and striatal VZ, as well as from the Su. In the cerebral wall, semF transcripts are found in a continuous band that includes the SP and layer VI, and occasionally extends into layer V. A weak semF signal is also beginning to appear in the cortical WM. (C) SemG transcripts are still expressed in the VZ, have become more pronounced in the WM and the Su, and in addition are now also present in the SP. (D)-(H) Higher magnification pictures, showing the cortical expression patterns in more detail for semF (D), semG $(\mathrm{F})$ and semD $(\mathrm{G})$ with adjacent Nissl-stained sections (E,H). (G) SemD transcripts are still present in the VZ (not shown), the SP and layer VI, but are now considerably reduced in layer V. Compare the different hybridization signals in layer VI: sparse and large-grain for semD, versus dense and fine for semF (D). (I) Coronal section through anterior cortex illustrating the appearance of the 'patchy' semG expression in the striatum. The continuous band of semG transcripts along the lateral striatal border may represent either the lateral migratory stream or the external capsule. (J), (K) Coronal sections through anterior and central cortex, respectively, hybridized with semF-specific probes. SemF is uniformly expressed in layer $\mathrm{V}$ of most cortical areas and in layer VI of dorsomedial (cingulate) cortex. In more lateral positions, semF transcripts within layer VI are distributed in discrete columnar patches that range between 150 and $500 \mu \mathrm{m}$ in width and span the entire dorsoventral extent of the layer. Arrowheads indicate individual patches. SemF hybridization is still present in the choroid plexus. (L) Nissl-stained coronal section through central cortex and adjacent sections hybridized with probes specific for semF (M) and semD (N). (M) SemF transcripts continue to be present in the thalamus and excluded from the TRN, and are now also clearly distinguishable in the region of the IC (arrow). (N) SemD is still expressed in the TRN and the striatum, but can no longer be found in the IC. The dotted line indicates the medial border of the TRN. CX: cortex, Su: subiculum, H: hippocampus, S: striatum, SP: subplate, WM: white matter, VZ: ventricular zone, IC: internal capsule, TRN: thalamic reticular nucleus, TH: thalamus. Scale bars: (A)-(C) and (I)-(K): $500 \mu \mathrm{m}$, (D)-(H): $100 \mu \mathrm{m},(\mathrm{L})-(\mathrm{N}): 250 \mu \mathrm{m}$. 

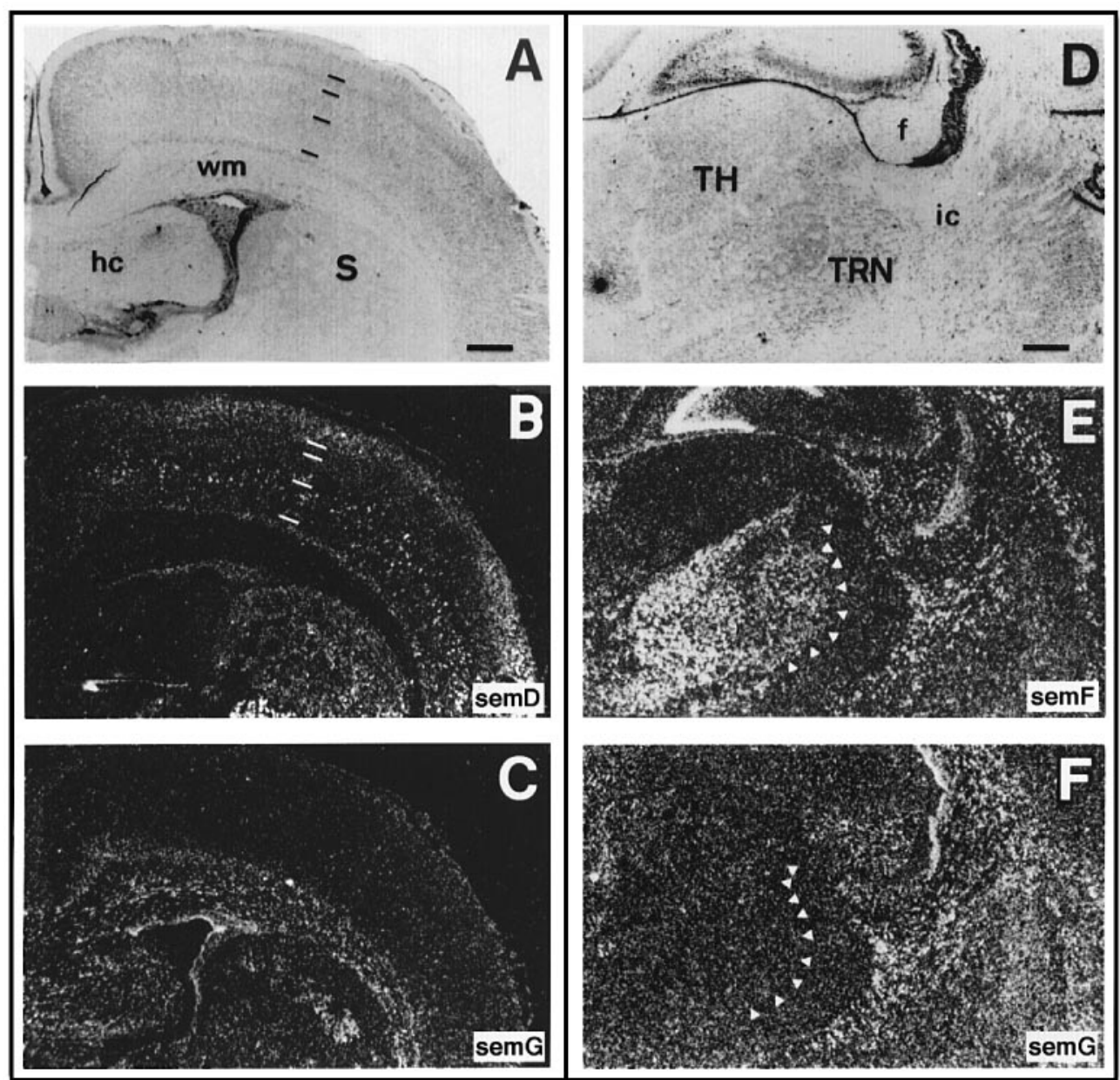

FIG. 6. Semaphorin expression at P5. Nissl-stained coronal sections from anterior (A) and central (D) cortex and adjacent sections hybridized with probes specific for semD (B), semF (E) and semG (C, F). Dorsal is to the top, medial to the left. Lines in (A) and (B) indicate the upper borders of layers IV, V, VI and SP, respectively. (B) SemD transcripts have disappeared from layer V and can now be found in the supragranular cortical layers. (C) SemG expression is maintained in the SP and the striatum, and increased in the WM and hippocampal commissure. (E) SemF transcripts can be found in the thalamus as before. In addition, semF is now strongly expressed in the IC and the fimbria (as well as in all fibre tracts throughout the brain). (F) SemG manifests a signal very similar to that of semF in both the IC and the fimbria, as well as in all the various fibre tracts. Arrows in (E) and (F) outline the medial border of the TRN. S: striatum, wm: white matter, hc: hippocampal commissure, ic: internal capsule, f: fimbria, TRN: thalamic reticular nucleus, TH: thalamus. Scale bars: (A)-(C): $500 \mu \mathrm{m},(\mathrm{D})-(\mathrm{F}): 250 \mu \mathrm{m}$.

\section{Expression of semaphorins in postnatal cortex}

At $\mathrm{P} 0$, the neuroepithelium is already markedly reduced and constitutes only a minor portion of the cortical sheet. Still, all four semaphorins (semC, D, F and G) continue to be expressed in this region (Fig. 4), and with the exception of semF that disappears before P2 (Fig. 5B), they remain expressed throughout the entire developmental period examined (Table 1).

During postnatal development there are three main changes in semaphorin distribution patterns in the cortex: (i) the gradual addition of semaphorin transcripts in the subplate; (ii) the onset of semF and $\mathrm{G}$ expression in the cortical white matter, and (iii) the appearance of semD and $\mathrm{F}$ in the differentiating cortical layers, first in the infragranular and subsequently in the supragranular layers. A more detailed chronological account of these changes is given in the following paragraphs.

At P0, semD transcripts appear in the SP (Fig. 4A), in addition to the continued expression of semF in this region. Initially, semD transcripts are only found in the anterior portions of the cortical sheet (Fig. 4J), suggesting that semD expression follows the cortical maturation gradient, according to which ventrolateral and anterior regions develop before dorsomedial and posterior areas (Angevine $\mathrm{Jr}$ \& Sidman, 1961; Berry \& Rogers, 1965; Luskin \& Shatz, 1985; Bayer \& Altman, 1991). Indeed, after P2 and throughout subsequent stages, semD transcripts are found in the SP of all cortical areas (Table 1; Figs 5D and 7B). In contrast, semF transcripts are restricted to the SP of the dorsomedial cortex and are absent from more ventrolateral positions along the cortical sheet (Fig. 4H). This distinctive expression pattern cannot be related to maturation gradients, as it persists throughout the developmental stages examined and is similar across the entire anteroposterior extent of the cortex. This constitutes the first instance of a regionally specific expression of a semaphorin gene along the tangential dimension.

Within the cortical layers, only semD and $\mathrm{F}$ are expressed and, at this stage ( $\mathrm{P} 0)$, they are confined to the differentiated infragranular layers. Both semD and $\mathrm{F}$ are found in layer V (Fig. 4A,B); semD is already evenly expressed across cortical areas (Fig. 4F,J), while semF mRNA is more pronounced in anterior cortex (Fig. 4G,K). Moreover, the semD expression domain occupies the entire width of layer $\mathrm{V}$ 
(Fig. 4F), whereas semF transcripts are more abundant in the middle and lower portions of this layer (Fig. 4G). These differences suggest that the two semaphorins are produced by different cellular subpopulations within layer $\mathrm{V}$.

Although cells in layer VI are generated before those in layer V, semaphorin expression in these layers follows the reverse order: at birth, semD and $\mathrm{F}$ are just beginning to be expressed in layer VI and
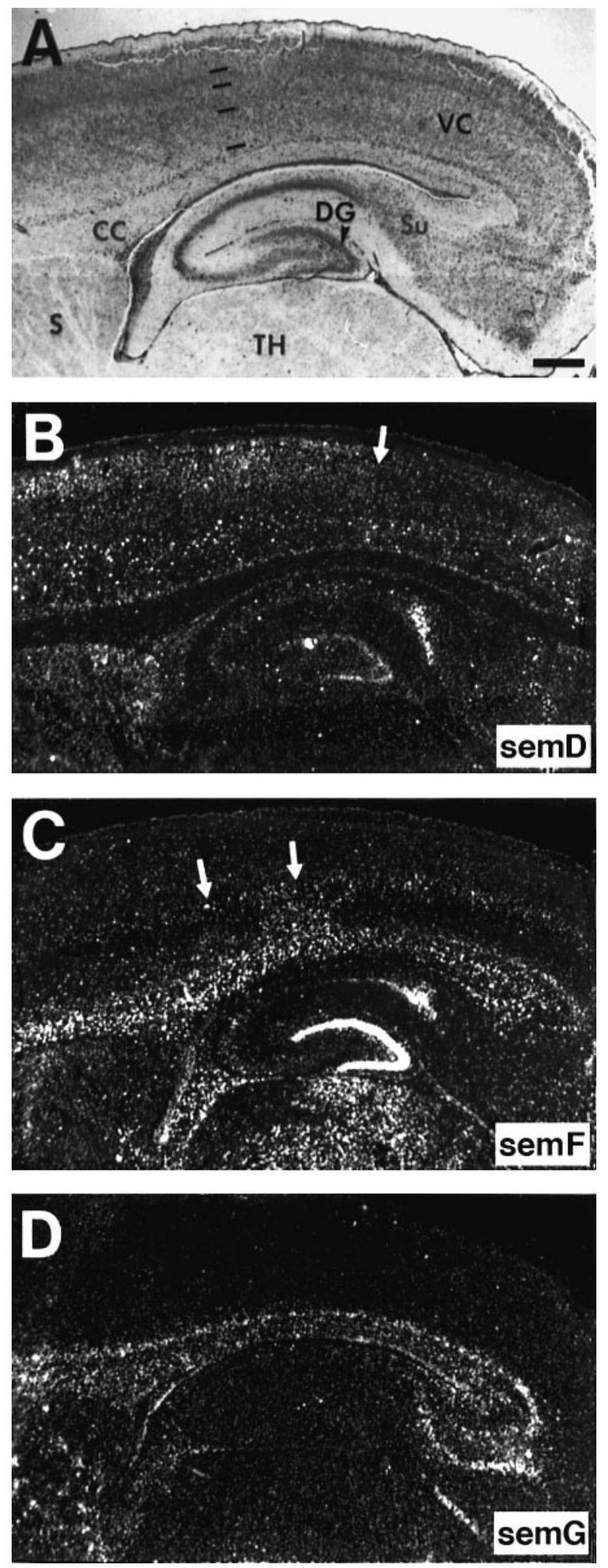

only in the most anterior portions of the cortex (Fig. 4J,K). It is only by $\mathrm{P} 2$ that semD and $\mathrm{F}$ hybridization signals extend to layer VI along the entire anteroposterior extent of the cortical sheet. SemD transcripts are distributed homogeneously throughout layer VI in relatively large and sparse grains (Fig. 5G). SemF, by contrast, exhibits finer and denser signals, and manifests different expression patterns in different cortical areas. In parasagittal sections taken from dorsomedial regions, semF transcripts distribute in a continuous band over the entire anteroposterior range, covering essentially the SP, layer VI, and occasionally the lower portion of layer V (Fig. 5B). Coronal sections at different anteroposterior planes reveal that this uniform semF expression is restricted mainly to the dorsomedial regions (cingulate cortex; Fig. 5J,K). More laterally, semF transcripts are homogeneously distributed in layer V (Fig. 5J,K), but in layer VI they form discrete 'columns' that are between 150 and $500 \mu \mathrm{m}$ wide, and span the entire dorsoventral extent of the layer. This patchy pattern is very prominent in anterior (Fig. 5J) and central (Fig. 5K) regions (putative somatosensory cortex), but not in posterior (putative visual) cortex. The qualitatively different hybridization signals-the homogeneous, sparse and large-grain label of semD versus the patchy, denser and finer label of semF-imply that these genes are expressed in different cell populations within this layer.

Also at this stage, semB (not shown) and semG (Fig. 5C) transcripts appear in the subplate in addition to the continued expression of semF and D. Before P2, semF hybridization in the SP appeared as a well delineated band, but the increasing accumulation of semF transcripts both below this layer, in the WM and in layer VI renders this expression domain less prominent (e.g. Fig. 5D). Nevertheless, semF is still clearly distinguishable in the SP and, as before, is essentially restricted to dorsomedial cortical regions (Fig. 5B,J). Unlike semF, semD and the newly expressed semB and $G$ signals distribute uniformly throughout cortical areas.

In the white matter, semaphorins begin to be expressed only perinatally: semG transcripts appear at $\mathrm{P}$, and those of semF at P2 (Table 1). Both hybridization signals increase with further maturation, are particularly pronounced in the middle of the dorsoventral extent of the WM (Fig. 5C,F) and resemble those seen in other major fibre tracts, e.g. the corpus callosum, hippocampal commissure (Fig. 6C) and internal capsule (Fig. 6E,F). None of the other semaphorin genes analysed is ever expressed in the WM.

FIG. 7. Semaphorin expression at P7. Nissl-stained parasagittal section (A) and adjacent sections illustrating the expression patterns for semD (B), semF (C) and semG (D). Dorsal is to the top, anterior to the left. The short lines in (A) indicate the upper borders of layers IV, V, VI and SP, respectively. (B) As before, semD transcripts can be found in the SP and layer VI, and are absent from layer V. Furthermore, although semD continues to be expressed in the supragranular cortical layers, now the signal is excluded from the most posterior regions, which correspond to the visual cortex. Arrow indicates the posterior limit of semD expression in the upper layers. Just anterior to this area, semD transcripts can also be detected in layer IV. (C) The expression domains of semF have not changed. In the cortex, semF can be found in layers V and VI, in the SP and in the WM. Consistent with the pattern seen at earlier ages, semF manifests a patchy expression in layer VI of the central (somatosensory) cortex (arrows) and disappears in posterior cortical regions (visual cortex). In addition, semF continues to be strongly expressed in the DG and TH, and can also be found in most fibre tracts, e.g. the CC and fimbria. (D) SemG expression has also remained constant, with transcripts present in the cortical VZ, WM, SP and striatum, where the patches are now more clearly defined. At this age, semG displays the strongest SP signal, compared to both semF and D. CC: corpus callosum, S: striatum, TH: thalamus, VC: visual cortex, DG: dentate gyrus, Su: subiculum. Scale bar: $500 \mu \mathrm{m}$. 
DEVELOPMENTAL EVENTS TC and CT axons grow through
the ganglionic eminence, avoiding the neuroepithelium

TC and CT axons restricted to the IZ and SP

TC axons do not yet invade the $\mathrm{CP}$

thalamic afferents invade the $\mathrm{CP}$

TC axons branch/synapse in layer VI
1

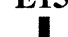

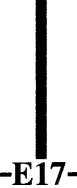

-E17-

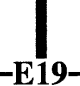

-E19

semF appears in SP

semB+C disappear from layer VI

semD disappears from the $\mathrm{CP}$

semF and $\mathbf{G}$ in neuroepithelium semD in ganglionic eminence

IZ and SP are devoid of semaphorin transcripts

$C P$ and $V Z$ contain multiple semaphorin transcripts last neurons migrate out of $\mathrm{VZ}$

TC terminals reach layer IV

TC terminals arborize in layer IV

SEMAPHORIN EXPRESSION 
SemF signals are the most pronounced throughout development and the earliest to appear. Detectable as early as E19 in the dentate gyrus (DG) and the subicular area (Fig. 3B), they also appear in CA1 by P0 (Fig. 4B). Hybridization is strongest at the border between subiculum and CA1, and gets progressively weaker towards CA3 (Fig. 4G,H). By P0, semD and $\mathrm{G}$ also begin to be expressed, semG in the subiculum (Fig. 4C), and semD in the dentate gyrus and at the junction between subiculum and CA1 (Fig. 4A,F). By P2, semF transcripts have again disappeared from the subiculum, while semG expression has increased further in this region (Fig. 5B,C). Moreover, semB mRNA now starts to appear in the CA1 and CA3 regions. No further changes in semaphorin expression patterns were found in the hippocampus beyond $\mathrm{P} 2$.

\section{Discussion}

In this report we present the first comprehensive account of developmental changes in the expression of five members of the semaphorin family in the mammalian forebrain. Our results reveal highly selective spatiotemporal patterns of expression, suggesting that semaphorins could be crucially involved in the development of di- and telencephalic structures. In the following, we discuss possible relations between semaphorin expression and the establishment of reciprocal connections between thalamus and cortex. We focus on this circuitry because its development has been thoroughly investigated, thus permitting the establishment of tight correlations between the timing of particular developmental events and semaphorin expression (Fig. 8). This discussion is based on the well documented chemorepulsive action of several semaphorins (Raper \& Kapfhammer, 1990; Kolodkin et al., 1992; Matthes et al., 1995; Messersmith et al., 1995; Adams et al., 1997). However, our knowledge of the range of functions of these molecules is still incomplete, and it needs to be considered that semaphorins, like other guidance molecules, may have heterogeneous effects whose polarity would depend on the receptors present on different cell types and axonal growth cones (e.g. Colamarino \& Tessier Lavigne, 1995). Our goal is to generate plausible hypotheses that can guide the design of further experiments in order to investigate the specific function of these molecules during development.

\section{Subcortical semaphorin expression during the establishment of the reciprocal connections between thalamus and cortex}

The first thalamocortical (TC) axons leave the diencephalon around E14 and grow through the ganglionic eminence (GE) within the basal telencephalon. At the same time, corticothalamic (CT) fibres travel in the opposite direction towards the thalamus. Both sets of axons avoid the proliferative neuroepithelium and confine their routes to the GE. The co-expression of the semC, F and $\mathrm{G}$ genes in the neuroepithelium (Table 1) is compatible with the interpretation that their products, separately or in combination, render this region nonpermissive for axon growth, thereby forcing fibres to deviate their route laterally, through the GE.

However, this route is not devoid of semaphorins, as semD is strongly expressed in the GE at the time when TC and CT fibres grow through this structure. SemD has been shown to repel sensory neurites in the spinal cord, and preliminary evidence indicates that it also inhibits thalamic and cortical fibres in culture (Bagnard et al., 1996). This apparent paradox could be resolved in three ways. One possibility is that TC and CT axons are not yet responsive to semD at this stage in development, as was shown for sensory fibres innervating the spinal cord (Püschel et al., 1996). Alternatively, inhibition of axonal extension by semD could be selectively overcome by permissive factors that allow growth in the presence of the repulsive protein. In principle, the simultaneous presence of attractive and repelling forces could increase the specificity of guidance signals and allow for a higher precision of axonal navigation. Notably, at this age, groups of cells within the GE have transient projections to the cortex and the thalamus, and are in close contact with CT and TC fibres (Mitrofanis \& Guillery, 1993; Métin \& Godement, 1996). These cell populations have been implicated as an intermediate target in the pathfinding of axons between thalamus and cortex, and they (or their projections) could provide a permissive substrate for the extension of axons through an otherwise hostile territory. A final possibility is that, in vivo, semD does not inhibit overall axon growth, but instead prevents branching and synapse formation, and/or causes fasciculation of axons. Such more subtle repulsive functions have been documented for semaphorins in other systems (Kolodkin et al., 1992; Kolodkin et al., 1993; Matthes et al., 1995) and are consistent with the characteristics of the fibre populations in this area. Within the ganglionic eminence, both TC and CT axons are organized in large fascicles that only break up into individual fibres upon leaving this region. Furthermore, these axons do not branch, and there is no evidence of synaptic contacts during early development (Ramcharan et al., 1995). In this way, semD could help to solve the general problem that presents itself when outgrowing axons need to traverse cell-dense regions without engaging in branching and synapse formation. At present, it is not possible to conclude which of these three alternatives is more likely, as all are equally plausible and consistent with published literature. However, knowledge of the precise expression patterns and how these are modified in the course of development will now allow us to test these hypotheses with the use of functional assays.

\section{Semaphorin expression in the cortex and its role in thalamocortical innervation}

Axons destined to leave the cortex take the shortest route out of the cortical plate, and once in the intermediate zone, grow tangentially within that layer until they reach the ventricular angle and turn into the basal telencephalon. At the same time, axons from the thalamus reach the lateral cerebral wall and grow dorsally within the IZ and SP layer. None of these axons enters the cortical neuroepithelium. This suggests that at this stage the cortical plate and the ventricular zone are hostile to CT and TC fibres, while the intermediate zone is permissive. This topology of hostile and permissive regions fits in nicely with the observed semaphorin expression domains. Both the $\mathrm{VZ}$ and $\mathrm{CP}$ contain high levels of several semaphorin transcripts, while semaphorin expression is very low in the IZ (Table 1). Thus, semaphorins appear to delineate the borders of territories through which axons are allowed to grow. Within this globally permissive zone, groups of fibres may be further sequestered based on their respective sensitivities to other diffusible factors, cell surface molecules or extracellular matrix cues (Sheppard et al., 1991; Bicknese et al., 1994; Miller et al., 1995; Henke-Fahle et al., 1996).

The subsequent changes in semaphorin distribution suggest that these molecules could also influence the onset of radial invasion of thalamic axons into the cortex. Tracing studies have shown that thalamic axons accumulate in the subplate for a variable and apparently species-dependent period before they invade the cortical plate (Rakic, 1977; Shatz \& Luskin, 1986; Catalano et al., 1991; Ghosh \& Shatz, 1992; Kageyama \& Robertson, 1993; Miller et al., 1993; Catalano et al., 1996). In the rat, substantial radial invasion occurs between E18 and E19, indicating that cortical permissiveness increases with differentiation. Tissue culture studies support this interpretation: at developmental stages preceding invasion the $\mathrm{CP}$ does not support 
ingrowth of thalamic axons (Molnár \& Blakemore, 1991; Götz et al., 1992), and both cortical and thalamic neurites grow better on membranes prepared from postnatal rather than embryonic cortex (Götz et al., 1992; Tuttle et al., 1995). It has been inferred from such studies that the onset of invasion is due to an upregulation of growth promoting molecules. However, both cortical and thalamic neurites are able to grow on embryonic membranes (Tuttle et al., 1995), and growth-promoting molecules, e.g. N-CAM and TAG-1, are present in the embryonic CP (Yamamoto et al., 1990; Chung et al., 1991; Wolfer et al., 1994). This suggests the alternative hypothesis that thalamic axons avoid the immature cortical plate because it transiently expresses inhibitory factors. Indeed, the spatio-temporal expression of semaphorins is consistent with this conjecture. SemD transcripts disappear from the CP between E17 and E19, matching both the onset of radial invasion and the increased permissiveness of cultured cortical explants. Thus, semD could act as a barrier for the ingrowth of thalamic afferents, a function analogous to its effect on sensory neurites (Püschel et al., 1995). In contrast, semB and C are still expressed in the $\mathrm{CP}$ at $\mathrm{E} 19$, as axons have begun their radial invasion. Their subsequent downregulation (Table 1) coincides with the time of increased branching and synapse formation in upper layer VI and lower layer V (Agmon et al., 1993; Kageyama \& Robertson, 1993; Catalano et al., 1996), suggesting that semB and C may prevent thalamic afferents from forming axon collaterals and synapses in these layers. Although the precise biological role of semB and C has not yet been determined, such functions have been associated with other members of the semaphorin family (Kolodkin et al., 1992; Matthes et al., 1995). Another possibility is that thalamic afferents are insensitive to semB and $\mathrm{C}$, and that these semaphorins control the ingrowth of other later developing inputs, such as cortico-cortical or callosal connections that also grow at that time and go through waiting periods below the cortical plate (Wise \& Jones, 1976; Olavarria \& Van Sluyters, 1985; Coogan \& Burkhalter, 1988).

Finally, the distribution of semD and F transcripts in the cortex suggests that these semaphorins are in the position to guide the formation of terminal arbors in layer IV. Thalamic afferents reach layer IV by P1-P2, just as layer IV neurons complete their migration and settle below the undifferentiated cortical plate. At this age, only semD and $\mathrm{F}$ are expressed in the cortex, and they are confined to the deep cortical layers V and VI. Consequently, layer IV is the first cortical layer encountered by ingrowing thalamic afferents that lacks semaphorins, and could therefore represent a preferred termination site. A similar, target-derived inhibition of terminal arborizations, has been ascribed to semaII in Drosophila (Matthes et al., 1995). The subsequent appearance of semD mRNA in supragranular layers at P5 (coinciding with their differentiation) is also compatible with semD inhibiting branching and synapse formation of TC axons: although occasional unbranched terminal arbors can be found in layers II/III, the vast majority of terminations remain in layer IV, where they continue to increase in density and complexity (Agmon et al., 1993).

We propose that cortical layers produce signals permissive for branching and synapse formation once they are sufficiently differentiated. Additional expression of semaphorins may subsequently serve to increase specificity by preventing innervation by inappropriate afferents. Tissue culture studies have shown that thamic axons growing into a cortical explant terminate in presumptive layer IV irrespective of whether they reach it from the pial or white matter side of the cortex (Molnár \& Blakemore, 1991; Bolz et al., 1992). Such results have been hitherto interpreted as indicative of an attracting stop-signal intrinsic to layer IV. However, the interpretation presented above, in which the stop-signal consists of the spatially localized absence of inhibitory cues, is similarly suited to explain these findings.

\section{Regional anisotropies in semaphorin expression}

Our results reveal conspicuous regional anisotropies in semD and $\mathrm{F}$ distributions in the subplate, in layer VI and in supragranular layers. The SP is believed to play an important role in the establishment of cortical circuitry (for reviews see: Shatz et al., 1990; Allendoerfer \& Shatz, 1994). Numerous molecules regulating developmental processes have been identified in the SP layer, including growth factor receptors, neuropeptides and extracellular matrix molecules (Chun et al., 1987; Stewart \& Pearlman, 1987; Chun \& Shatz, 1988; Allendoerfer et al., 1990; Naegele et al., 1991; Sheppard et al., 1991; Miller et al., 1995; Henke-Fahle et al., 1996). So far, however, regional specificity has not been demonstrated. Our data show that semF transcripts are restricted to the SP of dorsomedial cortex throughout its entire anteroposterior extent, suggesting that semF expression defines the dorsomedial position across the cortical sheet rather than marking individual cortical areas. This regionally specific distribution is probably not relevant to the selection of targets for thalamocortical afferents, which are already in place by then, but may be important for the routing of cortico-cortical or callosal projections which develop later. A second case of regional specificity is the patchy expression of semF in layer VI, which is restricted to central and anterior (sensorimotor) cortex. Its possible contribution to the pronounced compartmentalization of the barrel fields remains to be established. Finally, a third case of tangential specificity is the exclusion of semD from the supragranular layers of the posterior (presumably visual) cortex. At present, we are unaware of developmental processes that would distinguish visual from other cortical areas and could account for this anisotropy.

\section{Concluding remarks}

This study revealed a high degree of spatial and temporal specificity in the expression patterns of semaphorin genes, and the correlation of these patterns to particular developmental events suggests several possible functions for the corresponding proteins in cortical development (Fig. 8). The combined activities of different semaphorins could confine afferent fibres to particular pathways or cortical layers by rendering surrounding regions inaccessible. At the same time, by virtue of their specific expression patterns, semaphorins are in the position to promote the fasciculated state of thalamocortical and corticothalamic axons, and to prevent or restrict their branching and terminal arborizations. Precedents exist for such activities in several systems, but remain to be demonstrated in mammalian cortical development. The data presented here should allow us to test these predictions, by in vitro assays and genetic manipulations in rodents.

\section{Acknowledgements}

We thank Monika Sum, Ulrike Hoerbel and Christine Haas for excellent technical assistance, and William Hinkes for photographic work. We also thank Colin Blakemore for commenting on an early draft of the manuscript. This work was supported by grants from the Max-Planck-Gesellschaft, the Medical Research Council and the McDonnell-Pew Centre for Cognitive Neuroscience. I.S. currently holds a EC Research Training Grant.

\section{Abbreviations}

CP cortical plate

CT corticothalamic

DG dentate gyrus 


$\begin{array}{ll}\text { GE } & \text { ganglionic eminence } \\ \text { IC } & \text { internal capsule } \\ \text { IZ } & \text { intermediate zone } \\ \text { LGN } & \text { lateral geniculate nucleus } \\ \text { PFA } & \text { paraformaldehyde } \\ \text { PRN } & \text { perireticular nucleus } \\ \text { SP } & \text { subplate } \\ \text { TC } & \text { thalamocortical } \\ \text { TRN } & \text { thalamic reticular nucleus } \\ \text { VB } & \text { ventrobasal nucleus } \\ \text { VZ } & \text { ventricular zone } \\ \text { WM } & \text { white matter }\end{array}$

\section{References}

Adams, R.H., Betz, H. \& Püschel, A.W. (1996) A novel class of murine semaphorins with homology to thrombosporin is differentially expressed during early embryogenesis. Mech. Dev, 57, 33-45.

Adams, R.H., Lohrum, M., Klostermann, A., Betz. H. \& Püschel, A.W. (1997) The chemorepulsive activity of semaphorin $\mathrm{D}$ is regulated by furindependent proteolytic processing. EMBO J., 16, 6077-6086.

Agmon, A., Yang, L.T., O’Dowd, D.K. \& Jones, E.G. (1993) Organized growth of thalamocortical axons from the deep tier of terminations into layer IV of developing mouse barrel cortex. J. Neuroscience, 13, 5365-5382.

Allendoerfer, K.L. \& Shatz, C.J. (1994) The subplate, a transient neocortical structure: its role in the development of connections between thalamus and cortex. Annu. Rev. Neurosci., 17, 185-218.

Allendoerfer, K.L., Shelton, D.L., Shooter, E.M. \& Shatz, C.J. (1990) Nerve growth factor receptor immunoreactivity is transiently associated with the subplate neurons of the mammalian cerebral cortex. Proc. Natl. Acad. Sci. USA, 87, 187-190.

Altman, J. \& Bayer, S. (1995) Atlas of Prenatal Brain Development. CRC Press, Florida.

Angevine, J.B. Jr \& Sidman, R.L. (1961) Autoradiographic study of cell migration during histogenesis of cerebral cortex in the mouse. Nature, 192, 766-768.

Bagnard, D., Betz, H., Götz, M., Püschel, A.W. \& Bolz, J. (1996) Do semaphorins act as guidance molecules for afferent and efferent projections in the developing cerebral cortex? Soc. Neurosci. Abstr., 22, 1473.

Bayer, S.A. \& Altman, J. (1991) Neocortical Development. Raven Press, New York.

Behar, O., Golden, J.A., Mashimo, H., Schoen, F.J. \& Fishman, M.C. (1996) Semaphorin III is needed for normal patterning and growth of nerves, bones and heart. Nature, 383, 525-528.

Berry, M. \& Rogers, A.W. (1965) The migration of neuroblasts in the developing cerebral cortex. J. Anat., 99, 691-709.

Bicknese, A.R., Sheppard, A.M., O’Leary, D.D. \& Pearlman, A.L. (1994) Thalamocortical axons extend along a chondroitin sulfate proteoglycanenriched pathway coincident with the neocortical subplate and distinct from the efferent path. J. Neuroscience, 14, 3500-3510.

Bolz, J., Novak, N. \& Staiger, V. (1992) Formation of specific afferent connections in organotypic slice cultures from rat visual cortex cocultured with lateral geniculate nucleus. J. Neuroscience, 12, 3054-3070.

Catalano, S.M., Robertson, R. \& Killackey, H.P. (1996) Individual axon morphology and thalamocortical topography in developing rat somatosensory cortex. J. Comp. Neurol., 366, 36-53.

Catalano, S.M., Robertson, R.T. \& Killackey, H.P. (1991) Early ingrowth of thalamocortical afferents to the neocortex of the prenatal rat. Proc. Natl. Acad. Sci. USA, 88, 2999-3003.

Chun, J.J., Nakamura, M.J. \& Shatz, C.J. (1987) Transient cells of the developing mammalian telencephalon are peptide-immunoreactive neurons. Nature, 325, 617-620.

Chun, J.J. \& Shatz, C.J. (1988) A fibronectin-like molecule is present in the developing cat cerebral cortex and is correlated with subplate neurons. J. Cell Biol., 106, 857-872.

Chung, W.W., Lagenaur, C.F., Yan, Y.M. \& Lund, J.S. (1991) Developmental expression of neuronal cell adhesion molecules in the mouse neocortex and olfactory bulb. J. Comp. Neurol., 314, 290-305.

Clemence, A.E. \& Mitrofanis, J. (1992) Cytoarchitectonic heterogeneities in the thalamic reticular nucleus of cats and ferrets. J. Comp. Neurol., 322, 167-180.

Colamarino, S.A. \& Tessier Lavigne, M. (1995) The axonal chemoattractant netrin-1 is also a chemorepellent for trochlear motor axons. Cell, 81, 621-629.

Coogan, T.A. \& Burkhalter, A. (1988) Sequential development of connections between striate and extrastriate visual cortical areas in the rat. J. Comp. Neurol., 278, 242-252.

Crandall, J.E. \& Caviness, V.S. Jr (1984) Thalamocortical connections in newborn mice. J. Comp. Neurol., 228, 542-556.

Culotti, J.G. \& Kolodkin, A.L. (1996) Functions of netrins and semaphorins in axon guidance. Current Opinion in Neurobiol., 6, 81-88.

Dodd, J. \& Schuchardt, A. (1995) Axon guidance: a compelling case for repelling growth cones. Cell, 81, 471-474.

Earle, K.L. \& Mitrofanis, J. (1996) Genesis and fate of the perireticular thalamic nucleus during early development. J. Comp. Neurol., 367, 246-263.

Edelman, G.M. \& Crossin, K.L. (1991) Cell adhesion molecules: implications for a molecular histology. Annu. Rev. Biochem., 60, 155-190.

Emerling, D.E. \& Lander, A.D. (1994) Laminar specific attachment and neurite outgrowth of thalamic neurons on cultured slices of developing cerebral neocortex. Dev., 120, 2811-2822.

Friedlander, D.R., Milev, P., Karthikeyan, L., Margolis, R.K., Margolis, R.U. \& Grumet, M. (1994) The neuronal chondroitin sulfate proteoglycan neurocan binds to the neural cell adhesion molecules Ng-CAM/L1/NILE and N-CAM, and inhibits neuronal adhesion and neurite outgrowth. J. Cell Biol., 125, 669-680.

Fushiki, S. \& Schachner, M. (1986) Immunocytological 1?lization of cell adhesion molecules L1 and N-CAM and the shared carbohydrate epitope L2 during development of the mouse neocortex. Brain Res., 389, 153-167.

Gerfen, C.R. (1992) The neostriatal mosaic: multiple levels of compartmental organization. J. Neural Transm. (Suppl.), 36, 43-59.

Ghosh, A. \& Shatz, C.J. (1992) Pathfinding and target selection by developing geniculocortical axons. J. Neuroscience, 12, 39-55.

Giger, R.J., Wolfer, D.P., De Wit, G.M.J. \& Verhaagen, J. (1996) Anatomy of rat Semaphorin III/Collapsin-1 mRNA expression and relationship to developing nerve tracts during neuroembryogenesis. J. Comp. Neurol., 375, 378-392.

Goodman, C.S. \& Shatz, C.J. (1993) Developmental mechanisms that generate precise patterns of neuronal connectivity. Cell, 72, 77-98.

Götz, M., Novak, N., Bastmeyer, M. \& Bolz, J. (1992) Membrane-bound molecules in rat cerebral cortex regulate thalamic innervation. Development, 116, 507-519.

Henke-Fahle, S., Mann, F., Götz, M., Wild, K. \& Bolz, J. (1996) Dual action of a carbohydrate epitope on afferent and efferent axons in cortical development. J. Neuroscience, 16, 4195-4206.

Hortsch, M. \& Goodman, C.S. (1991) Cell and substrate adhesion molecules in Drosophila. Annu. Rev. Cell Biol., 7, 505-557.

Iijima, N., Oohira, A., Mori, T., Kitabatake, K. \& Kohsaka, S. (1991) Core protein of chondroitin sulfate proteoglycan promotes neurite outgrowth from cultured neocortical neurons. J. Neurochem., 56, 706-708.

Jessell, T.M. (1988) Adhesion molecules and the hierarchy of neural development. Neuron, 1(1), 3-13.

Kageyama, G.H. \& Robertson, R.T. (1993) Development of geniculocortical projections to visual cortex in rat: evidence early ingrowth and synaptogenesis. J. Comp. Neurol., 335, 123-148.

Kapfhammer, J.P., Grunewald, B.E. \& Raper, J.A. (1986) The selective inhibition of growth cone extension by specific neurites in culture. J. Neuroscience, 6, 2527-2534.

Kolodkin, A.L., Matthes, D.J. \& Goodman, C.S. (1993) The semaphorin genes encode a family of transmembrane and secreted growth cone guidance molecules. Cell, 75, 1389-1399.

Kolodkin, A.L., Matthes, D.J., O’Connor, T.P., Patel, N.H., Admon, A., Bentley, D. \& Goodman, C.S. (1992) Fasciclin IV: sequence, expression, and function during growth cone guidance in the grasshopper embryo. Neuron, 9, 831-845.

Lent, R., Hedin Pereira, C., Menezes, J.R. \& Jhaveri, S. (1990) Neurogenesis and development of callosal and intracortical connections in the hamster. Neuroscience, 38, 21-37.

Lochter, A., Vaughan, L., Kaplony, A., Prochiantz, A., Schachner, M. \& Faissner, A. (1991) J1/tenascin in substrate-bound and soluble form displays contrary effects on neurite outgrowth. J. Cell Biol., 113, 1159-1171.

Luo, Y., Raible, D. \& Raper, J.A. (1993) Collapsin: a protein in brain that induces the collapse and paralysis of neuronal growth cones. Cell, 75, 217-227.

Luo, Y., Shepherd, I., Li, J., Renzi, M.J., Chang, S. \& Raper, J.A. (1995) A family of molecules related to collapsin in the embryonic chick nervous system. Neuron, 14, 1131-1140.

Luskin, M.B. \& Shatz, C.J. (1985) Neurogenesis of the cat's primary visual cortex. J. Comp. Neurol., 242, 611-631.

Matthes, D.J., Sink, H., Kolodkin, A.L. \& Goodman, C.S. (1995) Semaphorin II can function as a selective inhibitor of specific synaptic arborizations. Cell, 81, 631-639. 
Messersmith, E.K., Leonardo, E.D., Shatz, C.J., Tessier Lavigne, M., Goodman, C.S. \& Kolodkin, A.L. (1995) Semaphorin III can function as a selective chemorepellent to pattern sensory projections in the spinal cord. Neuron, 14, 949-959.

Métin, C. \& Godement, P. (1996) The ganglionic eminence may be an intermediate target for corticofugal and thalamocortical axons. $J$. Neuroscience, 16, 3219-3235.

Miller, B., Chou, L. \& Finlay, B.L. (1993) The early development of thalamocortical and corticothalamic projections. J. Comp. Neurol., 335 , $16-41$.

Miller, B., Sheppard, A.M., Bicknese, A.R. \& Pearlman, A.L. (1995) Chondroitin sulfate proteoglycans in the developing cerebral cortex: the distribution of neurocan distinguishes forming afferent and efferent axonal pathways. J. Comp. Neurol., 355, 615-628.

Mitrofanis, J. (1992) Patterns of antigenic expression in the thalamic reticular nucleus of developing rats. J. Comp. Neurol., 320, 161-181.

Mitrofanis, J. \& Guillery, R.W. (1993) New views of the thalamic reticular nucleus in the adult and developing brain. TINS, 16, 240-245.

Molnár, Z. \& Blakemore, C. (1991) Lack of regional specificity for connections formed between thalamus and cortex in co-culture. Nature, 351, 457-477.

Molnár, Z. \& Blakemore, C. (1995) How do thalamic axons find their way to the cortex? TINS, 18, 389-397.

Naegele, J.R., Barnstable, C.J. \& Wahle, P.R. (1991) Expression of a unique $56-\mathrm{kDa}$ polypeptide by neurons in the subplate zone of the developing cerebral cortex. Proc. Natl. Acad. Sci. USA, 88, 330-334.

Olavarria, J. \& Van Sluyters, R.C. (1985) Organization and postnatal development of callosal connections in the visual cortex of the rat. J. Comp. Neurol., 239, 1-26.

Oohira, A., Matsui, F. \& Katoh-Semba, R. (1991) Inhibitory effects of brain chondroitin sulfate proteoglycans on neurite outgrowth from pc12d cells. J. Neuroscience, 11, 822-827.

Paxinos, G., Törk, I., Tecott, L.H. \& Valentino, K.L. (1991) Atlas of the Developing Rat Brain. Academic Press, London.

Pini, A. (1993) Chemorepulsion of axons in the developing mammalian central nervous system. Science, 261, 95-98.

Püschel, A.W., Adams, R.H. \& Betz, H. (1995) Murine semaphorin D/ collapsin is a member of a diverse gene family and creates domains inhibitory for axonal extension. Neuron, 14(5), 941-948.

Püschel, A.W., Adams, R.H. \& Betz, H. (1996) The sensory innervation of the mouse spinal cord may be patterned by differential expression of and differential responsiveness to semaphorins. Molec. Cell Neurosci., 7 , 419-431.

Püschel, A.W. (1996) The semaphorins: a family of axonal guidance molecules? Eur J. Neurosci., 8, 1317-1321.

Ragsdale, C.W. Jr \& and Graybiel, A.M. (1990) A simple ordering of neocortical areas established by the compartmental organization of their striatal projections. Proc. Natl. Acad. Sci. USA, 87, 6196-6199.
Rakic, P. (1977) Prenatal development of the visual system in rhesus monkey. Philos. Trans. $R$ Soc. Lond. B Biol. Sci., 278, 245-60.

Ramcharan, E.J., Adams, N.C. \& Guillery, R.W. (1995) A study of specialised membrane contacts in the developing rat perireticular nucleus. Soc. Nsci. Abstr., 21, 798.

Raper, J.A. \& Kapfhammer, J.P. (1990) The enrichment of a neuronal growth cone collapsing activity from embryonic chick brain. Neuron, 2, 12-29.

Schwab, M.E., Kapfhammer, J.P. \& Bandtlow, C.E. (1993) Inhibitors of neurite growth. Annu. Rev. Neurosci., 16, 565-595.

Shatz, C.J., Ghosh, A., McConnell, S.K., Allendoerfer, K.L., Friauf, E. \& Antonini, A. (1990) Pioneer neurons and target selection in cerebral cortical development. Cold Spring Harb. Symp. Quant. Biol., 55, 469-80.

Shatz, C.J. \& Luskin, M.B. (1986) The relationship between the geniculocortical afferents and their cortical target cells during development of the cat's primary visual cortex. J. Neuroscience, 6, 3655-3668.

Sheppard, A.M., Hamilton, S.K. \& Pearlman, A.L. (1991) Changes in the distribution of extracellular matrix components accompany early morphogenetic events of mammalian cortical development. J. Neuroscience, 11, 3928-3942.

Sperry, R.W. (1963) Chemoaffinity in the orderly growth of nerve fibre patterns and connections. Proc. Natl. Acad. Sci. USA, 50, 703-709.

Steindler, D.A., O'Brien, T.F. \& Cooper, N.G. (1988) Glycoconjugate boundaries during early postnatal development of the neostriatal mosaic. J. Comp. Neurol., 267, 357-369.

Stewart, G.R. \& Pearlman, A.L. (1987) Fibronectin-like immunoreactivity in the developing cerebral cortex. J. Neuroscience, 7, 3325-3333.

Tosney, K.W. \& Landmesser, L.T. (1984) Pattern and specificity of axonal outgrowth following varying degrees of chick limb bud ablation. J. Neuroscience, 4, 2518-2527.

Tuttle, R., Schlaggar, B.L., Braisted, J.E. \& O'Leary, D.D. (1995) Maturationdependent upregulation of growth-promoting molecules in developing cortical plate controls thalamic and cortical neurite growth. J. Neuroscience, 15, 3039-3052.

Van Eden, C.G. (1986) Development of connections between the mediodorsal nucleus of the thalamus and the prefrontal cortex in the rat. J. Comp. Neurol., 244, 349-359.

Wise, S.P. \& Jones, E.G. (1976) The organization and postnatal development of the commissural projection of the rat somatosensory cortex. J. Comp. Neurol., 168, 313-344.

Wolfer, D.P., Henehan Beatty, A., Stoeckli, E.T., Sonderegger, P. \& Lipp, H.P. (1994) Distribution of TAG-1/axonin-1 in fibre tracts and migratory streams of the developing mouse nervous system. J. Comp. Neurol., 345, 1-32.

Wright, D.E., White, F.A., Gerfen, R.W., Silos Santiago, I. \& Snider, W.D. (1995) The guidance molecule semaphorin III is expressed in regions of spinal cord and periphery avoided by growing sensory axons. J. Comp. Neurol., 361, 321-333.

Yamamoto, M., Hassinger, L. \& Crandall, J.E. (1990) Ultrastructural localization of stage-specific neurite-associated proteins in the developing rat cerebral and cerebellar cortices. J. Neurocytol., 19, 619-627. 